\title{
FATORES DETERMINANTES DO DISCLOSURE VOLUNTÁRIO SOB O ENFOQUE DA SUSTENTABILIDADE: UMA ANÁLISE DAS EMPRESAS DOS PAÍSES DO BRIC
}

\author{
Paulo Henrique Vieira Gomes \\ Mestre em Administração e Controladoria pela Universidade Federal do Ceará - UFC \\ Professor da Universidade Estadual do Ceará - UECE \\ phgomes@live.com \\ Márcia Martins Mendes De Luca \\ Doutora em Controladoria e Contabilidade pela Universidade de São Paulo - FEA/USP \\ Professora da Universidade Federal do Ceará - UFC \\ marciadeluca@ufc.br
Alessandra Carvalho de Vasconcelos
Doutora em Engenharia de Produção pela Universidade Federal de Santa Catarina - USFC
Professora da Universidade Federal do Ceará - UFC
alevasconcelos.ufc@gmail.com \\ Vera Maria Rodrigues Rodrigues Ponte \\ Doutora em Ciências Contábeis pela Universidade de São Paulo - FEA/USP \\ Professora da Universidade Federal do Ceará - UFC \\ vponte@fortalnet.com.br
}

\section{RESUMO}

Este estudo tem por objetivo investigar a relação entre as características econômico-financeiras das empresas e os respectivos níveis de disclosure voluntário de informações, sob o enfoque da sustentabilidade, em conformidade com as diretrizes do relatório da Global Reporting Initiative (GRI). Foram analisados os dados de 93 empresas de capital aberto dos quatro países do chamado Bric - Brasil, Rússia, Índia e China- que publicaram seus relatórios de sustentabilidade de 2010 no modelo GRI e elaboraram as demonstrações contábeis daquele exercício segundo as normas internacionais de contabilidade. Para tratamento dos dados, foi utilizada a Regressão Linear Múltipla. De forma geral, os resultados indicaram que os níveis de disclosure voluntário de informações voltadas para a sustentabilidade estão, de alguma forma, associados a incentivos econômicos. O desempenho e o tamanho afetaram positivamente o nível de disclosure, sugerindo que empresas maiores e com alto desempenho são capazes de influenciar os níveis de disclosure. Enquanto isso, a variável País afetou negativamente o nível de disclosure, indicando que empresas sediadas em países com IDH mais elevado possuem uma menor contribuição para a divulgação voluntária sob o enfoque da sustentabilidade, de acordo com as diretrizes do relatório GRI. As variáveis Rentabilidade, Endividamento e Impacto da atividade no meio ambiente não se mostraram significantes e, portanto, não são apontadas como fatores explicativos dos níveis de disclosure voluntário estudado.

Palavras-chave: Bric; Disclosure; Incentivos econômicos; Sustentabilidade.

\begin{abstract}
The present study aims at investigating the relationship between the economic and financial characteristics of companies and their respective levels of voluntary information disclosure from a sustainability point of view, in accordance to report guidelines from GRI, Global Reporting Initiative. Data from 93 public companies from socalled Bric countries (Brazil, Russia, India, and China) were analyzed. These companies published their 2010 GRI sustainability reports and produced their financial statements of that exercise according to international financial reporting standards. For the treatment of data, we used Multiple Linear Regression. In general, the five models indicated that the levels of voluntary information disclosure related to sustainability are, somehow, associated to financial incentive. The performance and size affect positively the level of disclosure, suggesting that larger and high performance companies proved capable of influencing disclosure levels. Meanwhile, the variable country negatively affected the level of disclosure, indicating that companies based in countries with higher HDI have a minor contribution to the voluntary disclosure from a sustainability approach, according to the guidelines of the GRI report. The variables profitability, indebtedness and environmental impact were not significant and therefore, are not identified as explanatory factors of voluntary disclosure levels.
\end{abstract}

Keywords: Bric; Disclosure; Financial incentive; Sustainability. 


\section{INTRODUÇÃO}

O desenvolvimento das empresas e de suas relações com o mercado induz uma maior divulgação de informações. Os órgãos reguladores procuram garantir a qualidade das informações divulgadas pelas empresas por meio da emissão de normas que tratam do conteúdo, da forma e da periodicidade de relatórios e demonstrativos, sendo, no entanto, impreciso determinar quais informações são efetivamente relevantes para os usuários.

No atual contexto do mercado, caracterizado pela emergência do conceito de sustentabilidade empresarial, percebe-se que, para atender às exigências dos stakeholders, as informações sobre a performance empresarial devem englobar, além de aspectos econômicos e financeiros, os aspectos sociais e ambientais, ou seja, as informações devem revelar aspectos intrínsecos à sustentabilidade das empresas. A divulgação de resultados, por meio de relatórios que evidenciem informações sob o enfoque da sustentabilidade, demonstra a preocupação da entidade em evidenciar seu desempenho sustentável para todas as partes interessadas em seu negócio, sendo este compreendido como o desempenho obtido a partir da condução da atividade voltada para o equilíbrio das relações entre as necessidades econômicas, ambientais e sociais, em longo prazo (Delai \& Takajashi, 2008; Albers \& Günther, 2010; Yrigay \& Respino, 2012; Fernandes, 2012; Holtz, Souza, Salaroli, \& Vargas, 2014).

Nesse sentido, percebe-se que o tema sustentabilidade tem sido amplamente discutido em âmbito governamental, empresarial, social e acadêmico. Ao longo das últimas décadas, além das pesquisas acadêmicas, que têm contribuído para a evolução do conceito de sustentabilidade e sua aplicabilidade (Moore \& Robson, 2001; Norman \& Macdonald, 2003; Ho \& Taylor, 2007), a demanda dos diversos stakeholders tem influenciado entidades de vários segmentos, exigindo uma postura transparente e a prestação de contas, por meio de informações mais claras para toda a gama de interessados.

O relatório de sustentabilidade de uma organização é, portanto, uma ferramenta de comunicação do seu desempenho social, ambiental e econômico. É um instrumento de prestação de contas não apenas para os investidores, mas também para a sociedade, sendo um espelho capaz de refletir a autoimagem, possibilitando os ajustes em direção à sustentabilidade.

Em países, tais como Austrália, Bélgica, Espanha, Holanda, Inglaterra e Portugal, a legislação prevê a obrigatoriedade de publicação de relatórios de sustentabilidade (Bernardo, Calegário, Pinto, \& Peçanha, 2005). Contudo, nos quatro países do grupo conhecido como Bric Brasil, Rússia, Índia e China - não há obrigatoriedade de publicação desse tipo de relatório; nem mesmo no Brasil, onde a legislação de proteção ambiental é bastante rigorosa (Holland \& Foo, 2003; Guse, Caraiani, Dascalu \& Lungu, 2009; Guttilla, 2010). Ainda que sem a exigência da lei, os princípios de sustentabilidade recomendam a comunicação e a interação das empresas com suas partes relacionadas, enquadrando-se nesse contexto o disclosure voluntário.

Levando-se em conta que a publicação de relatório de sustentabilidade não é obrigatória nos países do Bric e que, conforme ressalta Murcia (2009), as próprias características das empresas podem explicar o disclosure voluntário, este estudo está orientado para responder à seguinte questão: Há relação significante entre as características econômico-financeiras das empresas e a divulgação voluntária de informações sob o enfoque da sustentabilidade, nas empresas de capital aberto dos quatro países do Bric?

As razões que levam as empresas a divulgar determinadas informações adicionais, não obrigatórias, podem estar relacionadas ao interesse em benefícios econômicos proporcionados pela mesma. Há evidências empíricas de que, em muitos casos, os incentivos para a divulgação, e não os normativos em si, são fatores determinantes da qualidade das informações reportadas (Verrecchia, 1983; Dye, 1985; Burgstahler; Hail \& Leuz, 2006; Murcia, 2009; Albers \& Günther, 2010; Gamerschlag \& Möller; Verbeeten, 2010; Fernandes, 2012). Com base nesse contexto, esta pesquisa lança a hipótese de que a divulgação voluntária de informações sob o enfoque da sustentabilidade está relacionada com as características econômico-financeiras das empresas. 
Sob a abordagem teórica do disclosure voluntário, este estudo tem como objetivo geral investigar a relação entre as características econômico-financeiras das empresas dos quatro países do Bric - Brasil, Rússia, Índia e China - e os respectivos níveis de disclosure voluntário, em conformidade com as diretrizes do modelo G3 de relatório da Global Reporting Initiative (GRI). A opção pelos parâmetros ali definidos deve-se à sua consolidação e ao reconhecimento no mercado, conforme constatação feita por Brown, Jong e Levy (2009). Cabe ressaltar ainda, que o estudo não inclui a África do Sul - o que comporia o Brics -, pois as empresas de capital aberto listadas na Bolsa de Valores de Johannesburgo são obrigadas a publicar relatório de sustentabilidade, inviabilizando, dessa forma, a análise da divulgação voluntária de informações sob o enfoque da sustentabilidade.

A divulgação de informações de responsabilidade corporativa gera respaldo perante investidores e fomenta o convencimento da sociedade no tocante à adoção de uma postura socioambiental responsável. Dessa forma, a abordagem do tema referente ao disclosure voluntário de informações sob o enfoque da sustentabilidade é plenamente justificável, na medida em que a divulgação desses relatórios constitui importante canal de comunicação entre a entidade e seus stakeholders, no sentido de evidenciar seu desempenho econômico, social e ambiental. Além disso, a análise desse tipo de relatório possibilita que os stakeholders verifiquem o nível de comprometimento das empresas com os recursos sustentáveis.

Quanto aos procedimentos metodológicos, este estudo se classifica como quantitativo, assumindo um caráter explicativo quanto aos seus objetivos. Os dados da pesquisa foram coletados nos relatórios de sustentabilidade (modelo GRI-G3) publicados em 2011, referentes ao exercício de 2010, a partir dos websites das empresas e da GRI. Os dados econômico-financeiros foram obtidos nos websites das bolsas de valores dos quatro países e nos bancos de dados Economática ${ }^{\circledR}$ e Bloomberg®.

\section{DISCLOSURE VOLUNTÁRIO}

No elenco de disclosures de uma empresa, além das informações de caráter obrigatório, há um conjunto de informações não obrigatórias, mas que também são úteis para embasar as decisões dos usuários. Cabe ao gestor decidir quanto a importância e a conveniência de sua divulgação. Na seleção das informações a serem disponibilizadas para o mercado, faz-se necessária uma análise prévia da relação custo/benefício (Verrecchia, 2001). A divulgação não obrigatória denomina-se disclosure voluntário, ficando sua escolha a critério dos gestores e de acordo com os interesses da companhia.

A Teoria do Disclosure Voluntário é um arcabouço teórico de crescente pesquisa positiva internacional em contabilidade desde a década de 1980. Diversos estudos acadêmicos sobre o tema foram desenvolvidos, nacional e internacionalmente (Verrecchia, 1983; Dye, 1985; Burgstahler et al., 2006; Murcia, 2009; Albers \& Günther 2010; Gamerschlag et al.. 2010). Referidos estudos têm por principal objetivo explicar o fenômeno da divulgação de informações a partir de diversas perspectivas.

Segundo Yamamoto e Salotti (2006, p. 18), “[...] o disclosure voluntário pode ser classificado em três categorias, pela ótica da contabilidade: Eficiência, Associação e Discricionariedade". A categoria Eficiência diferencia-se das demais, por ser tratada como ex ante, ou seja, que indica previamente o tipo de divulgação mais apropriado aos usuários da informação. Desse modo, procura-se atingir a máxima eficiência por meio da divulgação de informações da preferência dos usuários. A categoria Associação considera o caráter exógeno do processo de divulgação, no qual se discute a relação entre a divulgação e as alterações nas ações dos usuários da informação. Nessa perspectiva, Machado e Ott (2015) revelam em seu estudo que as empresas utilizam o disclosure ambiental, por exemplo, como instrumento de legitimação social, empregando equilibradamente a forma pragmática, moral e cognitiva em sua forma de evidenciação. Na categoria Discricionariedade, os motivos da empresa (internos) passam a ser considerados (processo 
endógeno), de maneira que se questiona por que a empresa faz ou deixa de fazer a divulgação de determinadas informações.

Este estudo se fundamenta na última dessas três categorias propostas por Verrecchia (2001), baseada em discricionariedade, ao considerar que seu objetivo consiste em avaliar a relação de determinadas variáveis - características econômico-financeiras próprias das companhias - sobre a prática da divulgação voluntária.

Segundo Lopes e Martins (2007), a motivação para um comportamento discricionário de divulgação de informações pode ter origem na legislação tributária, na adequação de capital ou no gerenciamento de resultados contábeis. Os autores argumentam que há determinadas situações em que, mesmo na presença de uma estrutura de regras contábeis, a flexibilidade da regulamentação permite que os gestores utilizem a sua discricionariedade na escolha dos critérios contábeis que adotam e na maneira de dispor as informações.

Alguns estudos, tais como os de Hackston e Milne (1996), Mitton (2002), Nossa e Carvalho (2003), Eng e Mak (2003), Graham, Harvey e Rajgopal (2005), Burgstahler et al. (2006), Murcia (2009) e Gamerschlag et al. (2010), revelam que os incentivos para a divulgação, mais do que os próprios normativos em si, são determinantes da qualidade das informações reportadas pelas empresas.

Para Verrecchia (2001), a discricionariedade pode embasar-se em um julgamento objetivo, no qual os motivos que impulsionam as empresas a divulgar determinadas informações adicionais podem levar em conta aspectos econômico-financeiros, com o intuito de se obter benefícios econômicos.

De forma mais específica, Hackston e Milne (1996) analisaram as práticas de disclosure ambiental e social das companhias da Nova Zelândia e as variáveis que se relacionam a tais práticas. A pesquisa foi desenvolvida com base nos relatórios anuais das 50 maiores empresas neozelandesas, e os resultados, avaliados estatisticamente, mostraram que as variáveis Setor e Tamanho guardam correlação direta com os disclosures das empresas.

Durante a crise financeira do leste asiático nos anos 1997 e 1998, Mitton (2002) realizou um estudo relacionando os níveis de disclosure voluntário de informações econômicas com as características econômico-financeiras das empresas. Os resultados apontaram que as companhias auditadas por grandes empresas de auditoria, que têm ações negociadas em bolsas estrangeiras, que possuem menor concentração acionária e que apresentam menor diversidade de negócios exigem maiores níveis de disclosure do que as demais.

Em estudo que teve por objetivo investigar os níveis de disclosure de informações ambientais de empresas do setor de papel e celulose, Nossa e Carvalho (2003) constataram que os disclosures de informações ambientais divergem entre as companhias com relação ao tamanho da empresa, ao país de localização e ao tipo de relatório (financeiro ou específico).

Merece destaque também o estudo de Eng e Mak (2003), que utilizou uma amostra de 158 empresas da bolsa de valores de Singapura, para verificar a relação existente entre aspectos de governança corporativa e o disclosure voluntário, levando em conta a divulgação de informações estratégicas não-obrigatórias: financeiras e não-financeiras. Os resultados evidenciaram que incentivos econômicos como menor participação dos administradores e maior participação do governo na estrutura acionária de uma empresa, tamanho da firma e grau de endividamento estão associados a um maior nível de disclosure voluntário. Segundo os autores, a adoção de melhores práticas de governança resulta em maior controle das ações dos administradores, podendo-se, dessa forma, exigir mais disclosure.

Em Gamerschlag et al. (2010) foram analisados os fatores determinantes do disclosure voluntário nas 130 maiores empresas alemãs, a partir de um índice de divulgação de responsabilidade social corporativa elaborado com base nos indicadores dos relatórios no modelo da GRI. Os resultados evidenciaram que a divulgação voluntária é influenciada por incentivos 
econômicos como Estrutura acionária, Internacionalização, Rentabilidade, Tamanho e Setor de atividade.

No que tange à identificação de fatores indicativos dos níveis de evidenciação sobre as dimensões da sustentabilidade nos relatórios de empresas premiadas por suas práticas de responsabilidade social, no período entre 2009 e 2010, Costa, Torres, Vasconcelos e De Luca (2013) constataram que os fatores efeito do impacto da atividade no meio ambiente e a estrutura de propriedade do capital foram apontados como indicativos dos níveis de informações evidenciadas pelas empresas.

Especificamente sobre a relação entre o disclosure ambiental voluntário e o custo da dívida, Fernandes (2012) analisou as notas explicativas, o relatório da administração e o relatório de informações ambientais, de 2006 a 2010, de empresas listadas na BM\&FBovespa, e verificou que, no mercado brasileiro, as informações ambientais (positivas ou negativas) não impulsionam os credores à elevarem o custo do capital.

Ao analisar as empresas holandesas, Burgwal e Vieira (2014) comprovaram a existência de uma associação significativa e positiva entre o tamanho do setor e o nível de divulgação ambiental, porém, não observaram associação estatisticamente significativa entre a lucratividade e o nível de divulgação ambiental.

Bonfim, Teixeira e Monte (2015) verificaram a relação entre o disclosure da sustentabilidade e a governança corporativa em empresas de capital aberto não-financeiras listadas no IBrX-100 da BM\&FBovespa. Os resultados encontrados para o período de 2009 a 2011 demonstraram, dentre outros, que a administração familiar, a idade da companhia, o tamanho e o desempenho apresentaram efeito positivo no disclosure da sustentabilidade.

A relação entre o disclosure socioambiental e o desempenho de mercado também foi verificada por Santana, Góis, De Luca e Vasconcelos (2015), a partir dos relatórios, modelo GRI, de 114 empresas não-financeiras. Os autores verificaram que o disclosure socioambiental impacta positivamente o desempenho empresarial.

Este estudo utiliza como potenciais fatores determinantes da divulgação das informações voluntárias, sob o enfoque da sustentabilidade, as seguintes características empresariais: rentabilidade, desempenho no mercado de capitais, tamanho, endividamento, setor de atuação e país de localização. Essas características são apresentadas como potenciais fatores determinantes da divulgação das informações voluntárias sob o enfoque da sustentabilidade, consideradas para definição das hipóteses descritas a seguir e suas respectivas justificativas.

\section{MÉTODO DE PESQUISA}

Conforme classificação proposta por Selltiz, Jahoda, Deutsche e Cook (1974), esta pesquisa é definida como explicativa, com abordagem quantitativa, pois verifica o efeito causal de hipóteses, já que pretende analisar se a discricionariedade de empresas em divulgar informações voluntárias voltadas para a sustentabilidade está associada a suas próprias características.

Para delimitação da amostra, foram selecionadas as empresas de capital aberto dos quatro países do Brics que publicaram relatórios de sustentabilidade no modelo G3, de acordo com o banco de dados da GRI (2010), posição em 31/12/2011, relativamente ao exercício de 2010, e elaboraram suas demonstrações contábeis de 2010 em conformidade com as normas emanadas do International Accounting Standards Board (Iasb). A amostra reúne, portanto, 93 companhias abertas, sendo 56 do Brasil, 17 da Índia, 14 da China e 6 da Rússia.

Os dados econômico-financeiros foram extraídos das demonstrações contábeis das 93 empresas, disponibilizadas nos próprios websites corporativos e nos das bolsas de valores dos quatro países. As informações de mercado das empresas brasileiras foram coletadas na base de dados Economática ${ }^{\circledR}$, enquanto as das empresas dos outros três países foram extraídas da base de dados Bloomberg®. 
As informações econômico-financeiras em moeda de cada país foram convertidas para o padrão monetário dos EUA (US\$), por ser considerado a moeda funcional internacional (Montandon, Nunes \& Marques, 2005). As taxas de câmbio foram obtidas junto à International Finance Corporation (IFC). As contas patrimoniais e as informações de mercado foram convertidas à taxa cambial de 31 de dezembro de 2010, enquanto para as contas de resultado foi utilizada a taxa cambial média de 2010, conforme orientação da IAS 21 (IFRS, 2003).

Considerando a revisão de literatura apresentada nas seções anteriores (Nossa \& Carvalho, 2003; Eng \& Mak, 2003; Gamerschlag et al. 2010), certamente, a divulgação voluntária de informações está relacionada com as características das próprias empresas. Assim, as hipóteses desta pesquisa levam em conta as características das empresas, consideradas fatores potenciais que explicam os níveis de disclosure voluntário sob o enfoque da sustentabilidade, conforme os relatórios GRI-G3 das empresas em análise, detalhadas a seguir.

Hipótese 1: Empresas com mais rentabilidade apresentam maiores níveis de disclosure voluntário sob o enfoque da sustentabilidade.

A relação entre o disclosure e a rentabilidade foi analisada em estudos, tal como os de Albers e Günther (2010) e Dragomir (2010), os quais encontraram uma correlação positiva entre essas variáveis, justificando o fato de que empresas mais rentáveis tendem a divulgar mais informações com o objetivo de se diferenciar de empresas menos rentáveis e, assim, reduzir seu risco reputacional. Considera-se, nesta pesquisa, a variável Retorno sobre o Patrimônio (ROE) para se determinar a rentabilidade das empresas, que, de acordo com Assaf (2009), mensura o retorno dos recursos aplicados na organização por seus proprietários, medindo a eficiência da organização na aplicação de seus recursos próprios. O ROE é obtido por meio da divisão entre o Lucro Líquido e o Patrimônio Líquido.

Hipótese 2: Empresas com melhor desempenho no mercado de capitais apresentam maiores níveis de disclosure voluntário sob o enfoque da sustentabilidade.

Silveira, Leal, Carvalhal-Da-Silva e Barros (2007) relacionam o disclosure corporativo com um bom desempenho no mercado de capitais, interpretando a responsabilidade de prover informações voluntárias para os usuários como sendo uma dimensão de boa governança, esperando, dessa forma, uma relação positiva entre o disclosure e o desempenho no mercado de capitais.

Dentre as variáveis utilizadas para refletir o desempenho da empresa no mercado de capitais, amplamente aceita como proxy para o Desempenho no mercado de capitais, destaca-se a do Q de Tobin (Murcia, 2009). Assim como nos estudos de Murcia (2009) e Dragomir (2010), esta pesquisa utiliza o quociente de Tobin ajustado, conforme equação i:

$$
\mathrm{Q} \text { de Tobin }=\frac{\text { (Valor de Mercado das Ações }+ \text { Valor Contábil das Dívidas) }}{\text { Valor Contábil do Ativo Total }}
$$

Hipótese 3: Empresas de maior porte (tamanho) apresentam maiores níveis de disclosure voluntário sob o enfoque da sustentabilidade.

Os estudos de Reverte (2009), Gamerschlag et al. (2010) e Batres, Miller e Pisani (2010) corroboram os achados de Diamond e Verrecchia (1991), ao identificar uma correlação positiva entre a variável Tamanho e o nível de disclosure, justificando o incentivo econômico pelo fato de que empresas maiores, tendem a produzir informação com mais qualidade.

Neste estudo, a variável Tamanho é representada pelo valor do logaritmo da Receita Líquida, na busca de normalizar os dados referentes à variável e contribuir para a comparação com outras. A opção pela mensuração do tamanho, por meio da Receita Líquida, se deve ao fato de esta ser a melhor medida de comparação de empresas de atividades diferentes numa análise crosssectional, assim como a mais empregada nos estudos acerca do disclosure.

Hipótese 4: Empresas com maior endividamento apresentam maiores níveis de disclosure voluntário sob o enfoque da sustentabilidade. 
Por meio da Análise de Regressão, Reverte (2009), Dragomir (2010) e Albers e Günther (2010) comprovam o impacto do grau de endividamento sobre o disclosure voluntário. Esses autores salientam que as empresas com alto nível de endividamento são mais propensas a divulgação voluntária, pois precisam satisfazer os credores e mostrar-lhes que agem com transparência.

Entre os possíveis critérios de representação do endividamento discutidos na literatura contábil e financeira, optou-se por utilizar o indicador proposto por Ross, Westerfield e Jaffe (2002): Indicador de Endividamento Contábil, obtido pela razão entre o Passivo Exigível e o Ativo Total.

Hipótese 5: Empresas com atividade operacional de maior impacto ambiental apresentam maiores níveis de disclosure voluntário sob o enfoque da sustentabilidade.

O impacto da atividade de uma empresa ao meio ambiente também tem sido apontado como fator que afeta positivamente o nível de divulgação voluntária (Reverte, 2009; Murcia, 2009; Albers \& Günther, 2010).

Para analisar o efeito da atividade no meio ambiente sobre o disclosure voluntário, utilizase, como proxy, a variável dummy, a que se atribui peso "1" se a empresa pertence ao grupo de setores considerados de alto impacto ambiental, e peso " 0 " no caso contrário. Utilizou-se a classificação do dispositivo legal brasileiro, no caso a Lei $\mathrm{n}^{\circ} 10.165 / 2000$, que classifica as atividades potencialmente poluidoras a partir do grau de utilização dos recursos naturais: pequeno, médio e alto potencial de impacto ambiental.

Hipótese 6: Empresas de países mais desenvolvidos apresentam maiores níveis de disclosure voluntário sob o enfoque da sustentabilidade.

Este estudo adota o Índice de Desenvolvimento Humano (IDH) como proxy para análise da variável desenvolvimento do país. O IDH é uma medida comparativa usada para classificar os países pelo grau de "desenvolvimento humano": países desenvolvidos (elevado desenvolvimento humano), em desenvolvimento (médio desenvolvimento humano) e subdesenvolvidos (baixo desenvolvimento humano). A variável é construída a partir de dados, tais como expectativa de vida ao nascer, educação e PIB per capita (como um indicador do padrão de vida), recolhidos em nível nacional.

A partir dessas hipóteses operacionais, este estudo se propõe testar a existência de evidências estatísticas que comprovem a relação entre as características econômico-financeiras das empresas e os respectivos níveis de disclosure voluntário sob o enfoque da sustentabilidade.

Aplicou-se a técnica denominada Regressão Linear Múltipla. Conforme Fávero, Belfiore, Silva e Chan (2009, p. 346), essa técnica "[...] tem como objetivo estudar a relação entre duas ou mais variáveis explicativas, que se apresentam na forma linear". O estudo envolveu cinco regressões, sendo uma para cada nível de disclosure - aderência ao GRI, disclosure de informações econômicas, disclosure de informações ambientais, disclosure de informações sociais e disclosure de informações sob o enfoque da sustentabilidade -, todas definidas como variáveis dependentes. $\mathrm{O}$ modelo matemático da Regressão Linear Múltipla deste estudo é representado na equação ii.

$D I S=\alpha+\beta_{1} R E N T+\beta_{2} Q T O B+\beta_{3} T A M+\beta_{4} E N D+\beta_{5} I M P A C+\beta_{6} P A I S+\mu$ em que:

RENT $=$ Rentabilidade (Retorno sobre o Patrimônio - ROE)

QTOB $=Q$ de Tobin $=\frac{\text { (Valor de Mercado das Ações }+ \text { Valor Contábil das Dívidas })}{\text { Valor Contábil do Ativo Total }}$

$\mathrm{TAM}=$ Tamanho (Receita Líquida)

END $=$ Endividamento $\left(\frac{\text { PassivoExigível }}{\text { AtivoTotal }}\right)$

Impac = Impacto da atividade no meio ambiente (variável dummy: 1 se a atividade for de alto impacto ambiental e 0 se não for de alto impacto ambiental)

PaíS = Desenvolvimento do País (Índice de Desenvolvimento Humano - IDH) 
As métricas referentes à variável dependente (nível de disclosure voluntário) foram elaboradas com base nos indicadores do modelo de relatório de sustentabilidade, e envolvem cinco regressões, uma para cada medida de disclosure, a saber:

i) $\mathrm{DIS}_{\mathrm{GRI}}=$ Aderência ao Relatório GRI, que compreende o grau de atendimento das empresas ao modelo $\mathrm{G} 3$ medido em uma escala de seis níveis $(\mathrm{C}, \mathrm{C}+, \mathrm{B}, \mathrm{B}+, \mathrm{A}, \mathrm{A}+)$, pontuados de acordo com os indicadores considerados essenciais e não-essenciais do relatório da GRI;

ii) DIS $_{\mathrm{ECON}}=$ Disclosure de informações econômicas, relacionado à divulgação de informações de caráter econômico-financeiro, medido pelos indicadores EC1 a EC9;

ii) DIS $_{\text {АмB }}=$ Disclosure de informações ambientais, referente à divulgação de informações relacionadas à responsabilidade ambiental, medido pelos indicadores EN1 a EN30;

iv) DISsoc $=$ Disclosure de informações sociais, baseado na divulgação de informações relacionadas à responsabilidade social, medido pelos indicadores LA1 a PR9;

v) DISsust $=$ Disclosure de informações sob o enfoque da sustentabilidade, compreendendo todos os indicadores do relatório GRI (EC1 a PR9), envolvendo as dimensões econômica, ambiental e social.

A Regressão Linear Múltipla foi aplicada pelo método dos Mínimos Quadrados Ordinários (MQO), cujo objetivo consiste em obter a menor Soma de Quadrados dos Resíduos (SQR), ou seja, o menor erro possível (Coelho \& Cunha, 2007). O tratamento dos dados foi realizado com o auxílio do software Statistical Package for the Social Sciencies (SPSS), versão 20.

\section{ANÁLISE DOS RESULTADOS}

Inicialmente, para que os testes estatísticos apresentem plena validade, é necessário que o modelo - cinco modelos, no caso desta pesquisa - siga alguns pressupostos econométricos básicos referentes à regressão. Dessa forma, foram efetuados os seguintes testes: ausência de independência dos resíduos, multicolinearidade, normalidade dos resíduos e homocedasticidade.

O pressuposto de independência dos resíduos foi avaliado por meio do Teste de DurbinWatson, que, segundo Gujarati (2006), é utilizado para detectar a presença de autocorrelação (dependência) nos resíduos de uma análise de regressão, na suposição de que os erros no modelo de regressão são gerados por um processo autorregressivo de primeira ordem, que mede a correlação entre cada termo de erro e o termo de erro da observação imediatamente anterior (Gujarati, 2006). A Tabela 1 apresenta as estatísticas obtidas com o teste de Durbin-Watson nos cinco modelos de regressão deste estudo.

$\underline{\text { Tabela } 1 \text { - Teste de Durbin-Watson }}$

\begin{tabular}{lll}
\hline $\begin{array}{l}\text { Variável } \\
\text { Dependente }\end{array}$ & $\begin{array}{l}\text { Estatística } \\
\text { Durbin-Watson }\end{array}$ & Conclusão \\
\hline DISGRI & 1,794 & Ausência de autocorrelação serial \\
DISECON & 1,136 & Presença de autocorrelação serial \\
DISAMB & 1,015 & Presença de autocorrelação serial \\
DISSOC & 1,112 & Presença de autocorrelação serial \\
DISSUST & 0,837 & Presença de autocorrelação serial \\
\hline
\end{tabular}

Fonte: Elaborada pelos autores

Embora apenas a primeira regressão (DISGRI) apresente ausência de autocorrelação, este pressuposto não invalida as demais regressões, pois, segundo Fávero et al. (2009), a autocorrelação não se aplica aos modelos de regressão que apresentam dados em crosssection, que são dados observados em um determinado período, sem análise temporal.

A presença de multicolinearidade entre os regressores do modelo foi avaliada por meio do teste Variance Inflation Factor (VIF). Gujarati (2006) afirma que se o valor do VIF estiver acima de 10 há multicolinearidade problemática no modelo; se o VIF estiver entre 1 e 10 a multicolinearidade é aceitável; e se o referido valor estiver até 1 não há multicolinearidade no 
modelo de regressão. Portanto, o pressuposto, de acordo com o teste de multicolinearidade, é atendido, conforme apresentado na Tabela 2.

Tabela 2 - Teste de multicolinearidade: Variance Inflation Factor (VIF)

\begin{tabular}{lccccc}
\hline \multirow{2}{*}{ Variáveis dependentes } & \multicolumn{5}{c}{ Variance Inflation Factor (VIF) } \\
\cline { 2 - 6 } & DISGRI & DISECO & DISAMB & DISsOC & DISSUST \\
\hline Rentabilidade & - & - & - & - & - \\
Desempenho no mercado de capitais & - & 1,054 & 1,069 & 1,054 & 1,054 \\
Tamanho & 1,195 & 1,259 & 1,259 & 1,259 & 1,259 \\
Endividamento & - & - & - & - & - \\
Efeito da atividade no meio ambiente & - & - & 1,017 & - & - \\
País & 1,195 & 1,200 & 1,202 & 1,054 & 1,200 \\
\hline
\end{tabular}

Fonte: Elaborada pelos autores

A multicolinearidade entre os dados apresentou-se aceitável, visto que os resultados encontrados na estatística VIF chegaram até, no máximo, o valor de 1,259 referentes às variáveis independentes nos modelos de regressão múltipla analisados. Logo, os níveis de multicolinearidade dos modelos são aceitáveis.

A condição de normalidade dos resíduos não é necessária para a obtenção dos estimadores pelo método dos mínimos quadrados, mas sim para a definição de intervalos de confiança e testes de significância. A falta de normalidade é uma indicação de que os estimadores são não tendenciosos. A Tabela 3 apresenta o resultado dos testes Kolmogorov-Smirnov que analisam a normalidade dos resíduos.

Tabela 3 - Teste de normalidade dos resíduos

\begin{tabular}{ccc}
\hline Regressão & Kolmogorov-Smirnov & Conclusão \\
\hline DISGRI & 0,878 & Resíduos normais \\
DISECON & 0,191 & Resíduos normais \\
DISAMB & 0,907 & Resíduos normais \\
DISSOC & 0,680 & Resíduos normais \\
DISSUST & 0,818 & Resíduos normais \\
\hline
\end{tabular}

Fonte: Elaborada pelos autores

O pressuposto da normalidade dos resíduos foi realizado por meio do teste de KolmogorovSmirnov, o qual avalia se os valores de uma amostra têm distribuição semelhante, e, dessa forma, se esses valores podem ser considerados como provenientes de uma mesma população que segue distribuição padrão (Gujarati, 2006). Se o resultado do teste estatístico for superior ao valor crítico, ou seja, acima de 0,005, rejeita-se a hipótese nula de que os dados seguem a distribuição específica. Observou-se normalidade dos resíduos nas cinco regressões (p-valor superior a 0,005), indicando que os resíduos seguem distribuição normal.

O pressuposto da homocedasticidade (variância constante dos resíduos) foi avaliado por meio do Teste de Pesarán-Pesarán. A Tabela 4 apresenta as estatísticas obtidas, por meio deste teste, para as cinco regressões do estudo:

Tabela 4 - Teste de homoscedasticidade

\begin{tabular}{ccc}
\hline Regressão & Pesarán-Pesarán & Conclusão \\
\hline DISGRI & 0,172 & Resíduos homoscedásticos \\
DISECO & 0,177 & Resíduos homoscedásticos \\
DISAMB & 0,314 & Resíduos homoscedásticos \\
DISSOC & 0,669 & Resíduos homoscedásticos \\
DISSUST & 0,576 & Resíduos homoscedásticos \\
\hline
\end{tabular}

Fonte: Elaborada pelos autores 
O teste de Pesarán-Pesarán detecta a presença de homoscedasticidade com base nos resultados da regressão em que a variável dependente é o valor dos quadrados dos resíduos e a variável independente é o valor estimado da variável dependente original. Se houver uma relação significante entre as variáveis, rejeita-se a hipótese nula de homoscedasticidade (Coelho \& Cunha, 2007). Com base nos resultados, tal pressuposto foi aceito para todas as regressões, pois a estatística F do teste demonstrou valores superiores ao valor crítico de 0,005 , não apresentando significância.

Realizados os testes dos pressupostos das regressões (ausência de independência dos resíduos, multicolinearidade, normalidade dos resíduos e homoscedasticidade), são, a seguir, apresentados os resultados das cinco regressões efetuadas no estudo. Vale ressaltar que, para o período analisado, espera-se que as características econômico-financeiras das companhias abertas dos países do Bric influenciem positivamente os níveis de disclosure voluntário e a aderência ao relatório GRI.

\subsection{Análise dos níveis de disclosure e os incentivos econômicos}

A análise dos modelos de Regressão Linear Múltipla apresentou os resultados evidenciados na Tabela 5.

Tabela 5- Resultados dos modelos de regressão linear múltipla

\begin{tabular}{l|c|c|c|c|c}
\hline & $\begin{array}{c}\text { Regressão 1 } \\
\text { DISGRI }\end{array}$ & $\begin{array}{c}\text { Regressão 2 } \\
\text { DISECO }\end{array}$ & $\begin{array}{c}\text { Regressão 3 } \\
\text { DISAMB }\end{array}$ & $\begin{array}{c}\text { Regressão 4 } \\
\text { DISSOC }\end{array}$ & $\begin{array}{c}\text { Regressão 5 } \\
\text { DISSUST }\end{array}$ \\
\hline Rentabilidade & 0,006 & 0,033 & 0,044 & 0,013 & 0,027 \\
\hline Q de Tobin & $-0,036^{* * *}$ & $0,048^{*}$ & $0,047^{*}$ & $0,036^{* *}$ & $0,041^{*}$ \\
\hline Tamanho & $-0,134^{*}$ & $0,099^{*}$ & $0,102^{*}$ & $0,108^{*}$ & $0,105^{*}$ \\
\hline Endividamento & $-0,074$ & $-0,082$ & $-0,144^{*}$ & $-0,045$ & $-0,087$ \\
\hline Impacto & 0,036 & 0,028 & $0,164^{*}$ & 0,018 & 0,075 \\
\hline País & $1,706^{*}$ & $-0,849^{*}$ & $-1,036^{*}$ & $-1,072^{*}$ & $-1,033^{*}$ \\
\hline Número de observações & 93 & 93 & 93 & 93 & 93 \\
\hline $\mathrm{R}^{2}$ & 0,216 & 0,177 & 0,278 & 0,217 & 0,264 \\
\hline $\mathrm{R}^{2}$ ajustado & 0,233 & 0,120 & 0,227 & 0,163 & 0,213 \\
\hline $\begin{array}{l}\mathrm{F}(2,29) \\
\text { (p-valor) }\end{array}$ & $5,339 *$ & $3,090 *$ & $5,514^{*}$ & $3,977 *$ & $5,152^{*}$ \\
\hline Nota (*)Signif
\end{tabular}

Nota. (*)Significante ao nível de 1\%; (**)Significante ao nível de 5\%; (***) Significante ao nível de $10 \%$.

Fonte: Elaborada pelos autores

A Tabela 5 apresenta os resultados estatísticos dos cinco modelos de regressão utilizados no estudo; os coeficientes das variáveis independentes, que indicam a relação entre as variáveis; as quantidades de observações; os valores de $\mathrm{R}^{2}$ e $\mathrm{R}^{2}$ ajustado, que evidenciam o grau de explicação do modelo de regressão; e a estatística $\mathrm{F}$, que testa a significância dos modelos de regressão múltipla.

Apesar de as variáveis observadas representarem cerca de $20 \%$ das características explicativas do disclosore voluntário, conforme verificado pelos valores de $\mathrm{R}^{2}$ e $\mathrm{R}^{2}$ ajustado, o teste $\mathrm{F}$, para todas as regressões, apresentou-se significante, indicando que os modelos são válidos e é possível fazer inferência acerca de cada um deles, já que esse resultado sugere que a alteração em pelo menos uma das variáveis independentes explica a variável dependente de cada modelo (Fávero et al, 2009). Tal resultado é percebido a partir da significância dos modelos, que obtiveram p-valor inferior ao nível de significância adotado nesta pesquisa, de 5\%. O resultado desse teste indica que o modelo não é restrito, ou seja, é significante, com probabilidade de erro estatístico muito próximo de zero. Uma vez validados os modelos, faz-se necessário discutir os seus resultados.

\subsubsection{Nível de disclosure DISGRI (Aderência ao GRI)}

Analisando-se o nível de disclosure do DISGRI, que considera como variável dependente o nível de aderência ao relatório GRI, percebe-se que apenas duas variáveis independentes apresentaram significância, considerando o nível de 5\%: Tamanho e País. De acordo com os 
resultados dos coeficientes da Tabela 5, é possível perceber que, no DISGRI, a variável Tamanho possui uma relação inversa com o nível de disclosure, enquanto a variável País o influencia positivamente.

Ao se processar o primeiro modelo de regressão, considerando apenas as variáveis significantes, obtém-se a equação iii.

$D I S_{G R I_{i}}=-0,112 \times T A M_{i}+1,699 \times P A I S_{i}$

Quanto ao coeficiente de determinação ( $\mathrm{R}^{2}$ ajustado) da regressão DISGRI, pode-se inferir que 23,3\% do nível de disclosure relativo à aderência do relatório GRI é explicado pelas variáveis Tamanho e País. Além disso, o modelo de Regressão Linear Múltipla tem poder explicativo de $21,6 \%$, representado pelo $\mathrm{R}^{2}$ ajustado.

Conclui-se, assim, que as empresas de capital aberto pertencentes aos dois países do Bric com maiores IDHs, no caso a Rússia $(0,719)$ e o Brasil $(0,669)$, apresentam maiores níveis de aderência ao relatório GRI, comparativamente aos outros dois: China $(0,663)$ e Índia $(0,519)$. Enquanto isso, as empresas de menor porte, considerando Receita Líquida (variável Tamanho) no ano 2010, tendem a apresentar maiores níveis de aderência ao relatório GRI.

\subsubsection{Nível de disclosure econômico - DISECO}

Conforme a Tabela 5, o modelo de regressão DISECO possui, como variável dependente, o nível de disclosure voluntário econômico, medido a partir dos indicadores da dimensão econômica do relatório GRI. O referido modelo obteve as seguintes variáveis significantes: Q de Tobin, Tamanho e País, já que o p-valor dessas variáveis foi inferior a 0,05. Adicionalmente, verifica-se que a relação entre o nível de disclosure voluntário econômico e as variáveis $Q$ de Tobin e Tamanho é positiva, sendo negativa quando se faz a comparação com a variável País.

A partir do valor do $\mathrm{R}^{2}$, pode-se afirmar que $17,7 \%$ do nível de disclosure voluntário econômico foi explicado pelas variáveis $\mathrm{Q}$ de Tobin, Tamanho e País. O valor do $\mathrm{R}^{2}$ ajustado indica que a regressão múltipla tem poder explicativo de $12 \%$.

O modelo de regressão é apresentado matematicamente por meio da equação iv.

$$
D_{I S S_{E O}}=0,687+0,046 \times Q T O B I N_{i}+0,099 \times T_{A} M_{i}-0,829 \times P_{A I S}(i v)
$$

Logo, conclui-se que, com um modelo significante a um nível de 5\%, diferentemente do que se dá no modelo da primeira regressão analisada, as empresas dos países do Bric com IDHs (variável País) mais baixos divulgam mais informações relativas ao GRI, enquanto as empresas com melhor Desempenho no mercado de capitais (Q de Tobin) e de maior porte (variável Tamanho) tendem a intensificar a prática do disclosure de informações.

\subsubsection{Nível de disclosure ambiental - DISAMB}

Com relação ao DISAMB, que tem como variável dependente o nível de disclosure dos indicadores ambientais do relatório GRI, percebe-se que apresentaram significância, além da Constante, as variáveis Q de Tobin, Tamanho, Endividamento, Impacto e País, sendo essa relação de tal forma diversificada, que as variáveis $Q$ de Tobin, Tamanho e Impacto possuem relação positiva com a variável dependente, enquanto Endividamento e País refletem negativamente no nível de disclosure voluntário econômico.

Esse modelo indica ainda que $27,8 \%$ das alterações no referido nível de disclosure são explicadas pelo desempenho das empresas no mercado de capitais (Q de Tobin, Tamanho, Endividamento, Impacto e País). O poder explicativo do modelo foi de $22,7 \%$.

A representação matemática desse modelo é dada pela equação v. 
$D I S_{A M B_{i}}=0,794+0,048 \times Q T O B I N_{i}+0,102 \times T_{A M}-0,132 \times E N D_{i}+0,155 \times I M P A C_{i}-$ $1,052 \times P A I S_{i}$

Dessa forma, percebe-se que, com uma significância de 5\%, o nível de disclosure voluntário ambiental é maior nas empresas com melhor Desempenho no mercado de capitais, de maior porte e com atividade operacional de alto impacto no meio ambiente. Em contraponto, as empresas com maior endividamento e em países com IDH mais elevado apresentam menor nível de disclosure voluntário ambiental.

\subsubsection{Nível de disclosure social - DISSOC}

Conforme dados da Tabela 5, percebe-se que no modelo DISSOC, que tem como variável dependente o nível de disclosure voluntário social, as variáveis Constante, Q de Tobin, Tamanho e País foram significantes, pois apresentaram p-valor em proporção inferior a 5\%. Vale ressaltar que tal relação ocorre, de forma positiva, com as variáveis Q de Tobin e Tamanho, e negativa com a variável País.

A partir do coeficiente de determinação $\left(\mathrm{R}^{2}\right)$, infere-se que $21,7 \%$ do referido nível é explicado pelas variáveis significantes. Além disso, o poder explicativo da regressão múltipla, neste modelo, é de $16,3 \%$, representado pelo $\mathrm{R}^{2}$ ajustado.

O modelo obtido é apresentado na equação vi.

$D_{I S} S_{\text {OC }_{i}}=0,804+0,034 \times Q T O B I N_{i}+0,109 \times$ TAM $_{i}-1,058 \times$ PAIS $_{i}$ (vi)

$\mathrm{O}$ resultado dessa regressão indica que o melhor Desempenho no mercado de capitais (variável Q de Tobin) e o maior porte das empresas (variável Tamanho) podem influenciar positivamente o nível de disclosure voluntário social. Enquanto isso, as empresas de países com IDH mais elevados apresentam menores níveis de disclosure.

\subsubsection{Nível de disclosure sustentável - DISSUST}

No modelo de regressão relativo ao nível de disclosure voluntário sustentável, que consolida as dimensões econômica, ambiental e social, identificou-se significância nas variáveis Q de Tobin, Tamanho e País (Tabela 5). Destaca-se que o Q de Tobin e o Tamanho mostram uma relação positiva, enquanto a variável País apresenta relação inversa àquela relativa ao nível de disclosure.

Por meio da Tabela 5, é possível perceber ainda o poder explicativo do modelo, que é de 21,3\%. Além disso, observa-se que 26,4\% do nível de disclosure voluntário sustentável é explicado pelas variáveis Q de Tobin, Tamanho e País.

O modelo significante pode ser representado matematicamente por meio da equação vii.

$$
D I S_{\text {SUST }_{i}}=0,737+0,040 \times Q T O B I N_{i}+0,106 \times T_{A} M_{i}-0,999 \times P A I S_{i} \text { (vii) }
$$

No modelo DISSUST, a um nível de significância de 5\%, verifica-se que as empresas dos dois países do Bric com maiores IDHs (variável País) divulgam menos informações relativas ao GRI, enquanto empresas de maior porte (Tamanho) e com melhor Desempenho no mercado de capitais (Q de Tobin) tendem a praticar o disclosure de informações de forma mais intensa.

De uma forma geral, e a partir dos resultados dos modelos de regressão múltipla estimados, pode-se inferir que o comportamento do modelo DISGRI se opôs ao dos demais, já que estes evidenciaram relação positiva entre seus respectivos níveis de disclosure voluntário e a variável Tamanho, e relação negativa com a variável País, diferentemente do que foi observado no disclosure representado pela nota de aderência ao relatório GRI (modelo DISGRI). Além disso, o modelo DISGRI não apresentou significância a um nível de 5\% da variável Q de Tobin, enquanto os demais mostraram que tal variável impacta positivamente o nível de disclosure voluntário. 


\subsection{Discussão dos resultados e das hipóteses do estudo}

Os resultados indicam que as características aqui analisadas não representam em sua totalidade fatores determinantes dos níveis de disclosure voluntário das empresas da amostra.

A variável Rentabilidade, representada pelo ROE, não revelou uma relação estatisticamente significante em nenhum dos cinco níveis de disclosure voluntário, diferentemente dos resultados encontrados nos estudos de Yamamoto, Distadio e Fernandes (2007), Albers e Günther (2010), Dragomir (2010), que identificaram uma relação positiva entre o disclosure e a Rentabilidade, justificando o fato de que empresas mais rentáveis tendem a divulgar mais informações, com o objetivo de se diferenciar de empresas menos rentáveis e, assim, reduzir seu risco reputacional. Logo, a primeira hipótese operacional deste estudo, de que empresas com maior Rentabilidade apresentam maiores níveis de disclosure voluntário sob o enfoque da sustentabilidade, foi rejeitada. Cabe ressaltar que Burgwal e Viera (2014) também não encontraram associação entre lucratividade e disclosure ambiental. Pode-se explicar esse resultado pelo fato de que as empresas rentáveis já se diferenciam dos seus concorrentes no mercado de capitais com indicadores financeiros positivos, não sentindo a necessidade de divulgar informações.

A relação entre o Desempenho no mercado de capitais (variável Q de Tobin) e o disclosure voluntário apresentou, neste estudo, significância estatística para quatro dos cinco níveis de disclosure voluntário (econômico, ambiental, social e sustentável). Para o nível de disclosure, considerando o nível de aderência ao relatório GRI, a variável Desempenho no mercado de capitais não apresentou relação estatisticamente significante. Os resultados encontrados neste estudo corroboram os de Silveira et al (2007), Murcia (2009) e Santana et al. (2015), que identificaram uma relação positiva entre o Desempenho no mercado de capitais e o nível de disclosure, confirmando a hipótese de que um bom desempenho no mercado de capitais influencia positivamente o disclosure voluntário. Dessa forma, pode-se dizer que a segunda hipótese operacional desta pesquisa, de que empresas com melhor Desempenho no mercado de capitais apresentam maiores níveis de disclosure voluntário sob o enfoque da sustentabilidade, não foi rejeitada.

A variável Tamanho apresentou significância estatística nos cinco níveis de disclosure, demonstrando uma relação negativa para o nível de aderência ao relatório GRI. Isso indica que empresas maiores têm menores notas de aderência ao GRI e apresentam relação positiva nos demais níveis de disclosure, sinalizando que as empresas de maior porte apresentam maiores níveis de disclosure econômico, ambiental, social e sustentável. Esses resultados corroboram os estudos de Reverte (2009), Gamerschlag et al. (2010), Batres et al. (2010) e Bonfim et al. (2015), que também encontraram relação estatisticamente positiva entre o nível de disclosure e o Tamanho, justificando o incentivo econômico de que as empresas maiores tendem a ser mais organizadas no seu gerenciamento e na sua operacionalização e, consequentemente, possuem profissionais bem qualificados, possibilitando-lhes produzir informação com mais qualidade. Portanto, a terceira hipótese deste estudo não foi rejeitada, já que as empresas com maior Receita Líquida (variável Tamanho) apresentaram maiores níveis de disclosure voluntário sob o enfoque da sustentabilidade.

Quanto ao endividamento, os resultados obtidos rejeitaram a quarta hipótese, de que as empresas com mais endividadas apresentam maiores níveis de disclosure voluntário sob o enfoque da sustentabilidade, já que essa variável apresentou relação negativa com o nível de disclosure ambiental e não apresentou relação estatisticamente significante para os demais níveis de disclosure. Tais resultados divergem daqueles encontrados nos estudos de Depoers (2000), Reverte (2009), Dragomir (2010) e Albers e Günther (2010), segundo os quais as empresas com maior Endividamento tendem a apresentar maiores níveis de disclosure, já que precisam fornecer mais informações a seus acionistas e credores, para minimizar o problema de monitoramento entre as partes. Uma possível justificativa para essa divergência é que os stakeholders interessados na solvência da empresa não tenham interesse em informações de cunho ambiental.

Revista de Gestão Social e Ambiental - RGSA, São Paulo, v. 9, n. 2, p. 70-87, mai./ago., 2015. 
Assim como o grau de endividamento, a variável efeito da atividade no meio ambiente (Impacto) também apresentou relação estatisticamente significante apenas no nível de disclosure ambiental, obtendo-se a relação esperada deste estudo, na qual empresas com atividade operacional de maior impacto ambiental apresentam maiores níveis de disclosure voluntário sob o enfoque da sustentabilidade. Dessa forma, a quinta hipótese operacional também foi rejeitada. Os resultados corroboram as pesquisas de Reverte (2009), Murcia (2009) e Albers e Günther (2010), os quais constataram que as empresas com atividade operacional de maior impacto ambiental apresentam maiores níveis de disclosure voluntário, apenas no aspecto ambiental. Pode-se sugerir que as empresas que atuam em setores de maior impacto ambiental precisam realizar um esforço maior para viabilizar uma conciliação entre o resultado operacional e a preservação do meio ambiente, sofrendo maior pressão dos stakeholders, em comparação com as empresas com atividade operacional de menor impacto ambiental. Essa postura afetaria potencialmente apenas as práticas de divulgação voluntária de informações ambientais, não influenciando o disclosure de informações econômicas, sociais e, consequentemente, sustentáveis.

Observa-se, ainda, que a variável País, representada pelo IDH, apresentou significância estatística para os cinco níveis de disclosure voluntário. Assim, embora essa relação seja positiva apenas no nível de aderência ao relatório GRI, para os demais níveis, apresenta-se de forma negativa. Dessa forma, a sexta hipótese operacional deste estudo também foi rejeitada para quatro modelos (econômico, ambiental, social e sustentável), haja vista que o resultado esperado era que empresas de países mais desenvolvidos apresentassem maiores níveis de disclosure voluntário sob o enfoque da sustentabilidade, sendo que os resultados evidenciaram uma relação inversa. Nossa e Carvalho (2003), Reverte (2009) e Albers e Günther (2010) também identificaram o grau de desenvolvimento do país como potencial fator explicativo do nível de disclosure.

\section{CONSIDERAÇÕES FINAIS}

Esta pesquisa teve como objetivo geral investigar a relação entre as características econômico-financeiras das empresas dos quatro países do Bric e o disclosure voluntário, em conformidade com as diretrizes do modelo do relatório de sustentabilidade G3 da GRI. Para tanto, foram analisados os relatórios de sustentabilidade do ano 2010, publicados em 2011, de 93 empresas de capital aberto dos referidos países, elaborados nos padrões da GRI.

A partir dos resultados obtidos, e por meio da análise dos cinco modelos de Regressão Linear Múltipla estimados, pode-se inferir que o nível de disclosure voluntário de informações voltadas para a sustentabilidade pode estar associado com a preexistência de incentivos econômicos, o que permite a não-rejeição da hipótese geral deste estudo. Entretanto, vale salientar que foram identificadas divergências conforme os níveis de disclosure analisados, e algumas variáveis não se mostraram significantes, e, consequentemente, não se apresentaram como variáveis explicativas dos níveis de disclosure voluntário.

De forma mais pontual, ressalta-se que, levando-se em conta cada um dos níveis de disclosure admitidos neste estudo, os resultados foram diversificados. A Rentabilidade não se apresentou como fator explicativo do nível de disclosure em nenhum dos modelos considerados. Já o Desempenho no mercado de capitais e o Tamanho influenciaram positivamente os níveis de disclosure econômico, ambiental, social e sustentável. Portanto, pode-se inferir que, de uma maneira geral, as empresas de maior porte e com alto Desempenho no mercado de capitais são potencialmente mais transparentes quanto ao disclosure da sustentabilidade. Tal resultado não se repetiu quando considerada a aderência ao disclosure GRI, no qual o Tamanho influenciou negativamente o nível de disclosure, enquanto o Desempenho no mercado de capitais não apresentou coeficiente significante, sugerindo que esse fator não influencia o nível de disclosure GRI.

Enquanto isso, o Endividamento e o efeito da atividade no meio ambiente mostraram não influenciar os níveis de disclosure GRI, econômico, social e sustentável. Entretanto, o 
Endividamento mostrou influenciar negativamente o nível de disclosure ambiental, enquanto o Impacto da atividade influencia positivamente o disclosure ambiental, observando-se que as empresas, cujas atividades têm alto impacto no meio ambiente, disponibilizam mais informações da dimensão ambiental para os seus stakeholders. Já a variável País afetou negativamente os níveis de disclosure econômico, ambiental, social e sustentável, indicando que as empresas sediadas em países com IDH mais elevados fazem uma menor divulgação voluntária sob essas dimensões, ao passo que a variável País influencia positivamente os níveis de disclosure GRI das empresas.

Apesar de não ser objeto deste estudo, observa-se que seria relevante o estabelecimento de padrões de disclosure por órgãos reguladores e supervisores de cada país e de uma regulamentação internacional, que trate da divulgação de informações sob o enfoque da sustentabilidade, como forma de assegurar a aderência das empresas aos princípios da sustentabilidade, além de possibilitar meios de comparação dos níveis de disclosure das entidades com relação às suas práticas e a postura sustentável. Dessa forma, esse estudo contribui para a definição de eventuais políticas e estratégias de divulgação empresarial sob o enfoque da sustentabilidade.

Pode-se afirmar também, que os resultados da pesquisa contribuem para a ampliação da literatura sobre disclosure, considerando o enfoque da sustentabilidade, ainda escasso em economias emergentes e subdesenvolvidas, já que a maioria dos estudos sobre o tema, em geral, tem como amostra as empresas de mercados financeiros desenvolvidos, tal como o dos Estados Unidos e de países europeus.

Considerando-se as limitações desta pesquisa, em especial aquela relacionada ao espaço temporal analisado, recomenda-se a realização de nova análise, levando em conta relatórios de mais de um exercício. Sugerem-se ainda pesquisas para analisar o nível de disclosure de outro grupo de países com características socioeconômicas diferentes, a fim de possibilitar a comparação com os resultados aqui encontrados. Outra possibilidade de pesquisa nesse campo de estudo consiste em agregar, além de variáveis econômicas e financeiras das empresas, fatores culturais e institucionais dos países envolvidos.

\section{REFERÊNCIAS}

Albers, C., \& Günther, T. (2010) Disclosure or not disclosure: determinants of social reporting for STOXX Europe 600 firms. Zeitschriftfür Planung \& Unternehmenssteuerung, Online First ${ }^{\mathrm{TM}}, 22$ December. $\quad$ Recuperado em 20 fevereiro, 2013, de http://www.springerlink.com/index/C307U2550605JR67.pdf

Assaf, A. Neto. (2009) Finanças corporativas e valor. (4. ed.) São Paulo: Atlas.

Batres, L. A. P., Miller, V. V., \& Pisani, M. J. (2010) CSR, sustainability and the meaning of global reporting for Latin American corporations. Journal of Business Ethics, 91, 193-209.

Bernardo, D. C. R. B., Calegário, C. L. L., Pinto, L. B., Peçanha, G. R. G. (2005) Balanço social como ferramenta estratégica empresarial: um estudo dos demonstrativos sociais das sociedades anônimas de capital aberto no Brasil. In: Seminários em Administração FEA/USP - Semead, 8. Anais... São Paulo: USP.

Bonfim, E. T., Teixeira, W. D. S., \& Monte, P. A. (2015) Relação entre o disclosure da sustentabilidade com a governança corporativa: um estudo nas empresas listadas no Ibrx-100. Sociedade, Contabilidade e Gestão, 10(1), 6-28.

Lei $n^{\circ}$ 10.165, de 27 de dezembro de 2000. (2000). Altera a Lei $\mathrm{n}^{\circ} 6.938$, de 31 de agosto de 1981, que dispõe sobre a Política Nacional do Meio Ambiente, seus fins e mecanismos de formulação e aplicação, e dá outras providências. Recuperado em 1 agosto, 2012, de https://www.planalto.gov.br/ccivil_03/Leis/L10165.htm. 
Brown, H. S., Jong, M., \& Levy, D. L. (2009) Building institutions based on information disclosure: lessons from GRI's sustainability reporting. Journal of Cleaner Production, 17(1), 571-580.

Burgstahler, D. C., Hail, L., \& Leuz, C. (2006) The importance of reporting incentives: earnings management in European private and public firms. The Accounting Review, 81, 983-1.016.

Burgwal, D. V., \& Vieira, R. J. O. (2014) Determinantes da divulgação ambiental em companhias abertas holandesas. Revista Contabilidade \& Finanças - USP, 25(64), 0-78.

Coelho, A. C., \& Cunha, J. V. A. (2007) Regressão linear múltipla. In: Corrar, L. J., Paulo, E., \& Dias-Filho, J. M. (Coord.). Análise multivariada: para os cursos de administração, ciências contábeis e economia. São Paulo: Atlas, 131-231.

Costa, M. I., Torres, L. S., Vasconcelos, A. C., \& De Luca, M. M. M. (2013) Classificação do conteúdo dos relatórios de sustentabilidade de empresas premiadas por suas práticas de responsabilidade socioambiental. Revista de Educação e Pesquisa em Contabilidade, 7(2), 147-166.

Delai, I., \& Takajashi, S. (2008) Uma proposta de modelo de referência para mensuração da sustentabilidade corporativa. Revista de Gestão Social e Ambiental, 2(1), 19-40.

Depoers, F. A. (2000) Cost benefit study of voluntary disclosure: some empirical evidence from French listed companies. European Accounting Review, 9, 245-263.

Diamond, D., \& Verrecchia, R. (1991) Disclosure, liquidity and the cost of capital. Journal of Finance,46, 1.325-1.360

Dragomir, V. D. (2010) Environmentally sensitive disclosures and financial performance in a European setting. Journal of Accounting \& Organizational Change, 6(3), 359-388.

Dye, R. (1985) Disclosure of nonproprietary information. Journal of Accounting Research, 23, 123145.

Eng, L. L., \& Mak, Y. T. (2003) Corporate governance and voluntary disclosure. Journal of Accounting and Public Policy, 22, 325-345.

Fávero, L. P., Belfiore, P., Silva, F. L., \& Chan, B. L. (2009) Análise de dados: modelagem multivariada para a tomada de decisões. Rio de Janeiro: Campus.

Fernandes, S. M. (2012) Nível do disclosure ambiental das empresas brasileiras listadas na BM\&FBovespa: uma análise do período de 2006 a 2010. Revista de Gestão Social e Ambiental, 6(2), 106-120.

Gamerschlag, R., Möller, K., \& Verbeeten, F. (2010) Determinants of voluntary CSR disclosure: empirical evidence from Germany. Review of Managerial Science, 10, 10-52.

GRI - Global Reporting Initiative. About. (2010) Recuperado em 24 julho, 2012, de http://www.globalreporting.org.

Graham, J. R., Harvey, C. R., \& Rajgopal, S. (2005) The economic implications of corporate financial reporting. Journal of Accounting and Economics, 40(1-3), 3-73. 
Gujarati, D. N. (2006) Econometria básica. (4 ed.) Rio de Janeiro: Elsevier.

Guse, G. R., Caraiani, C., Dascalu, C., \& Lungu, C. I. (2009) Innovations in social and environmental reporting based on the knowledge of stakeholders' information needs. The Journal of the Faculty of Economics, 3, 979-985.

Guttilla, R. W. (2010). Relatórios de sustentabilidade: devem ou não devem ser obrigatórios no Brasil? São Paulo. Recuperado em 15 janeiro, 2013, de http://www.ibgc.org.br/Download.aspx?Ref=Eventos\&CodArquivo=259.

Hackston, D., \& Milne, M. J. (1996) Some determinants of social and environmental disclosures in New Zealand companies. Accounting, Auditing \&Accountability Journal, 9(1), 77-108.

Ho, L. J., \& Taylor, M. E. (2007) An empirical analysis of triple bottom line reporting and its determinants: evidence from the United States and Japan. Journal of International Financial Management \& Accounting, 18(2), 123-150.

Holland, L., \& Foo, Y. B. (2003) Differences in environmental reporting practices in the UK and the US: the legal and regulatory context. The British Accounting Review, 35, 1-18.

Holtz, L., Souza, J. A., Salaroli, A. R., \& Vargas, L. H. F. (2014) Divulgação de informações de caráter social e ambiental nos websites das maiores empresas com atividades no Espírito Santo. Revista de Gestão Social e Ambiental, 8(2), 36-48.

IFRS - International Financial Reporting Standards. (2003) IAS 21 - the effects of changes in foreign exchange rates. Dec.

Lopes, A. B., \& Martins, E. (2007) Teoria da contabilidade: uma nova abordagem. São Paulo: Ed. Atlas.

Machado, D. P., \& Ott, E. (2015) Estratégias de legitimação social empregadas na evidenciação ambiental: um estudo à luz da teoria da legitimidade. Revista Universo Contábil, 11(1), 136-156.

Mitton, T. A. (2002) Cross-firm analysis of the impact of corporate governance on the East Asian financial crisis. Journal of Financial Economics, 64, 215-241.

Montandon, M. M., Nunes, A. A. A., \& Marques, J. A. V. C. (2005) Conversão de demonstrações contábeis pelo SFAS 52: um estudo sobre a propriedade da adoção do dólar justo na Aracruz Celulose S/A. In: Congresso Internacional de Custos, 9. Anais... Florianópolis: CBC.

Moore, G., \& Robson, A. (2001) Corporate social and financial performance: an investigation in the UK supermarket industry. Journal of Business Ethics, 34, 299-315.

Murcia, F.D. (2009) Fatores determinantes do nível de disclosure voluntário de companhias abertas no Brasil. 182 f. Tese (Doutorado em Ciências Contábeis) -Programa de Pós-Graduação em Ciências Contábeis, Universidade de São Paulo, São Paulo.

Nossa, V., \& Carvalho, L.N. G. (2003) Uma análise do conteúdo do disclosure ambiental de empresas do setor de papel e celulose em nível internacional. In: Encontro da Associação Nacional de Pós-Graduação e Pesquisa em Administração, 27. Anais... Rio de Janeiro, Anpad. 
Norman, W., \& Macdonald, C. (2003) Getting to the bottom of "Triple Bottom Line". Virginia, EUA: Business Ethics Quarterly.

Reverte, C. (2009) Determinants of corporate social responsibility disclosure ratings by Spanish listed firms. Journal of Business Ethics, 88, 351-366.

Ross, S. A., Westerfield, R. W., \& Jaffe, J. E. (2002) Administração financeira: corporate finance. (2. ed.) São Paulo: Atlas.

Santana, L. M., Góis, A. D., De Luca, M. M. M., \& Vasconcelos, A. C. (2015) Relação entre disclosure socioambiental, práticas de governança corporativa e desempenho empresarial. Revista Organizações em Contexto, 11(21), 49-72.

Selltiz, C., Jahoda, M., Deutsch, M., \&Cook, S. W. (1974) Métodos de pesquisa nas relações sociais. São Paulo: EPU.

Silveira, A. D., Leal, R. P. C., Carvalhal-Da-Silva, A., \& Barros, L. A. B. C. (2007) Evolution and determinants of firm-level corporate governance quality in Brazil. Social Science Research Network, junho. Recuperado em 2 agosto, 2012, de http://papers.ssrn.com/sol3/papers.cfm?abstract_id=995764.

Verrecchia, R. E. (1983) Discretionary disclosure. Journal of Accounting and Economics, 5, 179194.

Verrecchia, R. E. (2001) Essays on disclosure. Journal of Accounting and Economics, 22, 97-180. Yamamoto, M. M., Distadio, L. F., \& Fernandes, R. C. (2007) Environmental disclosure in the mining sector in Latin America and South Africa. Easdi Environmental Accounting Sustainable Development Indicators. Praga: Czech Statistical Office, 1, 33-34.

Yamamoto, M. M., \& Salotti, B. (2006) Informação contábil: estudos sobre sua divulgação no mercado de capitais. São Paulo: Atlas.

Yrigay, H. A., \& Respino, R. M. (2012). Estudo de caso comparativo entre o modelo de sustentabilidade adotado pela ANTF e o modelo GRI. Revista de Administração da Unimep, 10(3), 243-262.

Recebido em: 20/04/2015

Publicado em: 04/08/2015 